\title{
РАЗРАБОТКА МЕТОДИКИ РАСЧЕТА КОЛИЧЕСТВА ВОЗДУХА, ТРЕБУЕМОГО ДЛЯ ПРОВЕТРИВАНИЯ ТУПИКОВЫХ ПРОХОДЧЕСКИХ ВЫРАБОТОК ПОСЛЕ ВЗРЫВНЫХ РАБОТ
}

\author{
Е.В. КОЛЕСОВ \\ Горный институт УрО РАН, г. Пермь
}

\begin{abstract}
Аннотация: Приведены результаты трехмерного численного моделирования вентиляции тупиковой горной выработки после взрывных работ с использованием программного комплекса ANSYS CFX. Показано, что в тупиковой выработке в случае нагнетательного способа проветривания образуются две зоны, механизмы проветривания которых имеют принципиальные отличия. Получена формула расчета требуемого количества воздуха, учитывающая турбулентное перемешивание в зоне смешения выработки и конвективный вынос вредных примесей из оставшейся части выработки.

Ключевые слова: вентиляция горных выработок, трехмерное численное моделирование, турбулентность, требуемое количество воздуха, взрывные работы, зона смешения
\end{abstract}

\section{Введение}

В настоящее время при расчете требуемого количества воздуха для проветривания тупиковых проходческих выработок в большинстве рудников определяющим является фактор выхлопных газов от машин с двигателями внутреннего сгорания (ДВС). При этом в последние годы имеет место тенденция перехода от ДВС к электродвигателям, и на первый план будет выходить фактор загазования выработок после взрывных работ. На многих горнодобывающих предприятиях России для расчета необходимого для разбавления газов свежего воздуха используют формулу временной инструкции по расчету количества воздуха, необходимого для проветривания рудных шахт 1983 года, которая является неудовлетворительной для корректных вычислений, поскольку основана на весьма сильных упрощениях и в большинстве случаев дает завышенные значения требуемых расходов, что противоречит требованиям энергоэффективности проветривания рудников. В связи с этим необходимо разработать методику, позволяющую корректно рассчитывать требуемое количество воздуха для проветривания тупиковых проходческих выработок после взрывных работ.

\section{Постановка задачи}

Исследуется тупиковая горная выработка в период после проведения взрывных работ, проветриваемая струей воздуха, подаваемого по вентиляционному трубопроводу с помощью вентилятора местного проветривания (ВМП), расположенного в сквозной выработке на свежей струе воздуха. Схема проветривания тупиковой проходческой выработки представлена на рис. 1.

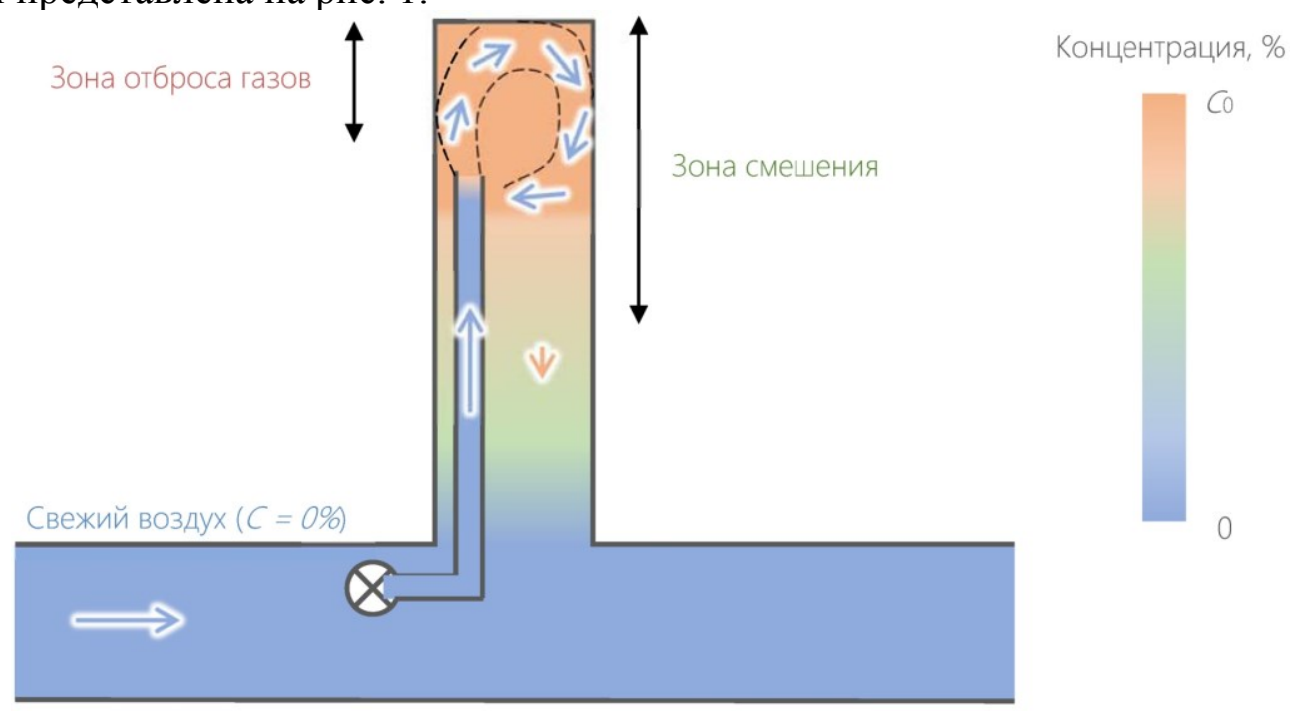

Рис. 1. Схема проветривания тупиковой выработки после взрывных работ 
После взрывных работ в призабойной части тупиковой выработки образуется так называемая зона отброса газов с ненулевой концентрацией ядовитых газов. В специализированной литературе существует множество эмпирических формул, предложенных разными авторами на основании различных натурных исследований, по которым рассчитывается длина зоны отброса газов [1]. При этом значения длины зоны отброса газов для одних и тех же исходных данных, посчитанные по этим формулам, могут существенно отличаться друг от друга, в связи с чем применимость этих формул необходимо определять в каждом конкретном случае и по возможности подтверждать экспериментально. В настоящей работе показано, что время проветривания тупиковой выработки не зависит (в пределах 5\% погрешности) от длины зоны отброса газов, а зависит от начальной средней концентрации ядовитых газов в зоне смешения области вблизи забоя с разнонаправленным движением воздуха (при нагнетательном способе проветривания), в которой происходит интенсивное перемешивание чистого и загазованного воздуха. Объем зоны смешения рассчитывается, как объем выработки, ограниченный грудью забоя и сечением выработки, после которого движение воздуха всюду направлено к устью выработки. Таким образом, время, необходимое для проветривания тупиковой выработки после взрывных работ, рассчитывается как сумма времени разбавления концентрации вредных газов до предельно допустимых концентраций (ПДК) в зоне смешения и времени однократного воздухообмена в оставшемся объеме проветриваемой выработки.

Изменение средней концентрации газовой примеси $C(t)$ в объеме зоны смешения $V_{3 C}$ описывается моделью В.Н. Воронина [2], которая представляет собой уравнение баланса массы примеси в объеме зоны смешения с начальным условием:

$$
\left\{\begin{array}{c}
\frac{d C(t)}{d t}-K \frac{Q}{V_{3 c}} C(t)=0 \\
C(0)=C_{0}=\frac{A b}{V_{3 c}}
\end{array}\right.
$$

где $K$ - безразмерный коэффициент эффективности проветривания; $Q$ - расход воздуха, выходящий из воздуховода, ${ }^{3} / \mathrm{c} ; A$ - масса одновременно взрываемого взрывчатого вещества (BВ), кг; $b$ - удельное газовыделение, или газовость, ВВ в пересчете на условную окись углерода, $\mathrm{m}^{3} / \kappa г$.

Решением системы (1) является функция:

$$
C(t)=C_{0} \exp \left(-\frac{K \cdot Q}{V_{3 c}} t\right)
$$

Соответственно, количество воздуха $Q$, необходимое для проветривания объема зоны смешения $V_{3 c}$ за время $t$ до ПДК, вычисляется по формуле:

$$
Q=\frac{V_{\text {зс }}}{K \cdot t} \ln \left(\frac{C_{0}}{C_{\text {пдк }}}\right) \text {. }
$$

В полученном решении фигурируют два неизвестных параметра: объём зоны смешения и коэффициент эффективности проветривания. Для их оценки была разработана трехмерная численная модель проветривания тупиковой выработки на основе методов вычислительной гидродинамики. В настоящее время в литературе представлено множество работ, связанных с применением методов CFD для решения задач рудничной вентиляции Г3-71.

В данной работе параметры исходной модели следующие: сечение тупиковой выработки - арочное, плошадь сечения $17 \mathrm{~m}^{2}$, длина выработки - 50 м; воздуховод находится вблизи стенки у кровли выработки, диаметр воздуховода -1 м, скорость воздушной струи на выходе из воздуховода - 10 м/с, расстояние между забоем выработки и концом воздуховода - 10 м. В расчетах использовалась модель турбулентности

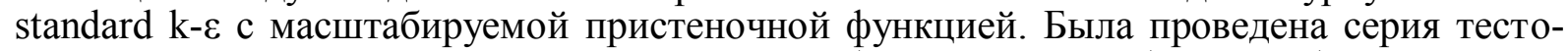
вых расчетов на независимость решения от выбора сетки, и выбрано разбиение расчетной области на сетку, состоящую из тетраэдрических элементов с размером $10 \mathrm{~cm} \mathrm{co}$ сгущением вблизи стенок выработки и воздуховода, где также задавался призматический пограничный слой. Шаг по времени был выбран 0,5 секунды (рис. 2).

На рис. 3 представлены линии тока воздуха в тупиковой выработке, полученные в результате моделирования. В области вблизи забоя образуется крупномасштабный вихрь, от формы и размеров которого зависит скорость и эффективность выноса вредных примесей из зоны смешения. 


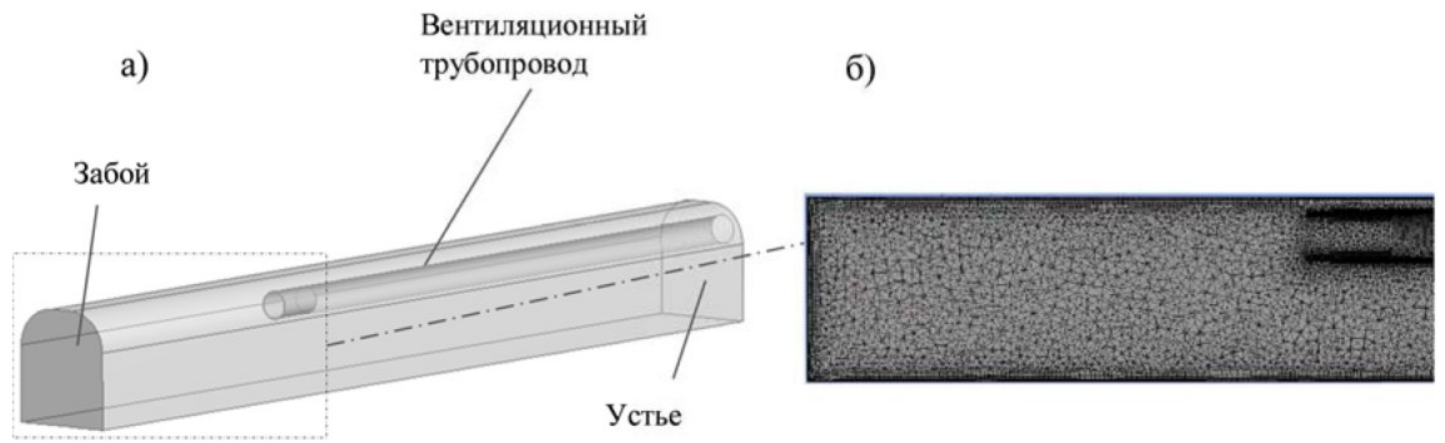

Рис. 2. а) расчетная область модели, б) дискретизация области на конечные объемы

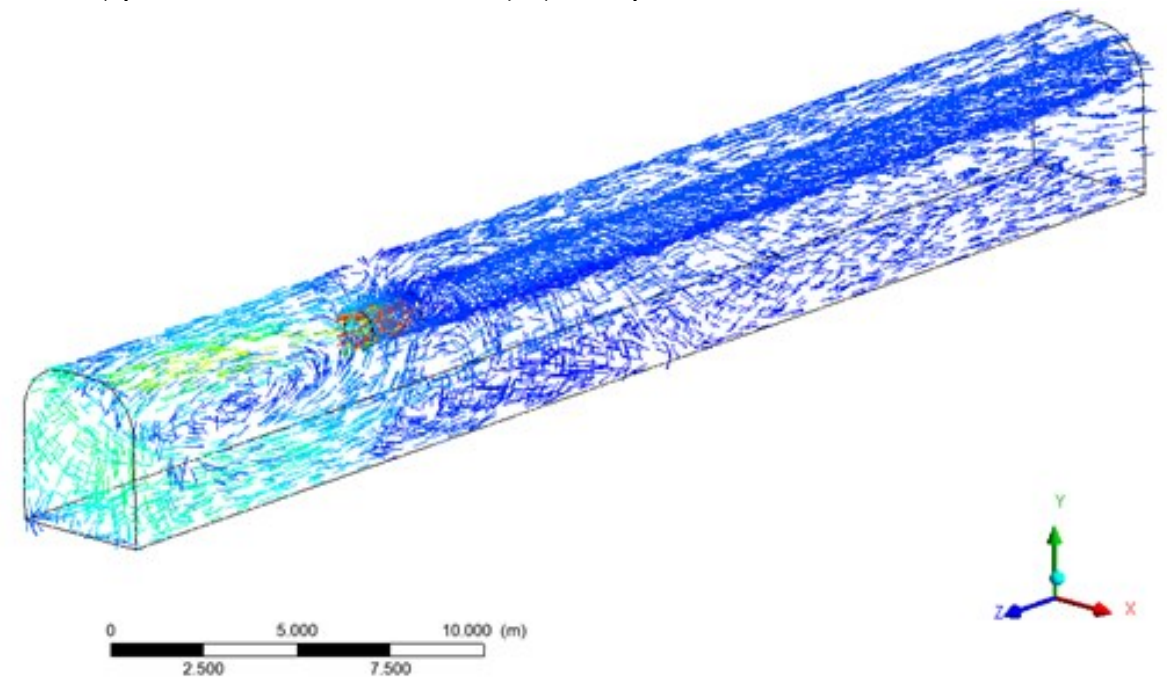

Рис. 3. Линии тока воздуха в тупиковой выработке

Для оценки размера зоны смешения была проведена серия расчетов для различных сечений тупиковой выработки и различных отставаний трубопровода от груди забоя. В результате расчетов получена формула для определения объема зоны смешения $V_{\text {зс }}$ и длины зоны смешения $L_{3 c}$ :

$$
\begin{gathered}
V_{3 \mathrm{c}}=L_{3 \mathrm{c}} \cdot S, \\
L_{3 \mathrm{c}}=L_{\text {от }}+\frac{16 \cdot \sqrt{S}}{k_{\text {выр }}},
\end{gathered}
$$

где $L_{\text {от }}$ - отставание вентиляционного трубопровода от груди забоя, м; $S$ - площадь поперечного сечения тупиковой выработки, $\mathrm{m}^{2} ; k_{\text {выр }}$ - коэффициент, учитывающий форму выработки, принимается по таблице 1.

Таблица 1

\section{Коэффициент формы выработки}

\begin{tabular}{|l|c|}
\hline \multicolumn{1}{|c|}{ Форма сечения выработки } & Значение $k_{\text {выр }}$ \\
\hline Арочная & 3,77 \\
\hline Квадратная & 4 \\
\hline Прямоугольная & 4,04 \\
\hline Круглая & 3,54 \\
\hline
\end{tabular}

Для исследования зависимости времени проветривания зоны смешения от длины зоны отброса газов были рассчитаны модели с длиной зоны отброса газов 1 м и длиной, равной длине зоне смешения (при этом массы и газовость ВВ оставались прежние). Времена проветривания зон смешения до ПДК в этих случаях отличались в пределах 5\%.

Таким образом, нет необходимости оценивать длину зоны отброса газов, достаточно считать только начальную среднюю концентрацию в зоне смешения по формуле:

$$
C(0)=\frac{A b}{V_{3 \mathrm{c}}} \text {. }
$$


В результате моделирования были получены значения коэффициента эффективности проветривания $K$ в зависимости от сечения выработки и отставания трубопровода от груди забоя. Поскольку полученные значения варьировались от 0,6 до 1,86, то при расчете количества воздуха в случае отсутствия исходных данных следует принимать наименьшее значение, что соответствует наименее эффективному выносу вредных примесей.

Таким образом, количество воздуха, требуемое для проветривания тупиковой проходческой выработки после взрывных работ, рассчитывается по формуле:

$$
Q=\frac{L_{\text {зс }} \cdot S}{K \cdot t} \ln \left(\frac{100 A \cdot b}{L_{\text {зс }} \cdot S \cdot C_{\text {пдк }}}\right)+\frac{\left(L-L_{\text {зс }}\right) \cdot S}{t}, \mathrm{~m}^{3} / \mathrm{c},
$$

в которой коэффициент эффективности проветривания принимается равным 0,6 ; $C_{\text {пдк }}$ - предельно допустимая концентрация окиси углерода, \%.

На рис. 4 в качестве сравнения представлены графики зависимости требуемого расхода свежего воздуха для проветривания тупиковой проходческой выработки после взрывных работ от длины выработки для сечений $10 \mathrm{~m}^{2}, 16 \mathrm{~m}^{2}, 30 \mathrm{~m}^{2}$, рассчитанные по формуле (8) и формуле временной методики 1983 г.:

$$
Q=\frac{2,25}{t} \sqrt[3]{\frac{A \cdot b \cdot S^{2} \cdot L^{2} \cdot k_{\text {обв }}}{k_{\text {ут }}^{2}}}, \mathrm{M}^{3} / \mathrm{c} .
$$

Значения входящих в формулы параметров следующие: $\mathrm{A} / \mathrm{S}=19,4$ кг/м2; $\mathrm{b}=0,07$ м3/кг в пересчете на условную окись углерода $(\mathrm{CO}) ; \mathrm{K}=0,6 ; \mathrm{t}=60$ мин; $\mathrm{kyт}=1 ;$ кобв $=$ $1 ;$ СпдкСО =0,0017\%.

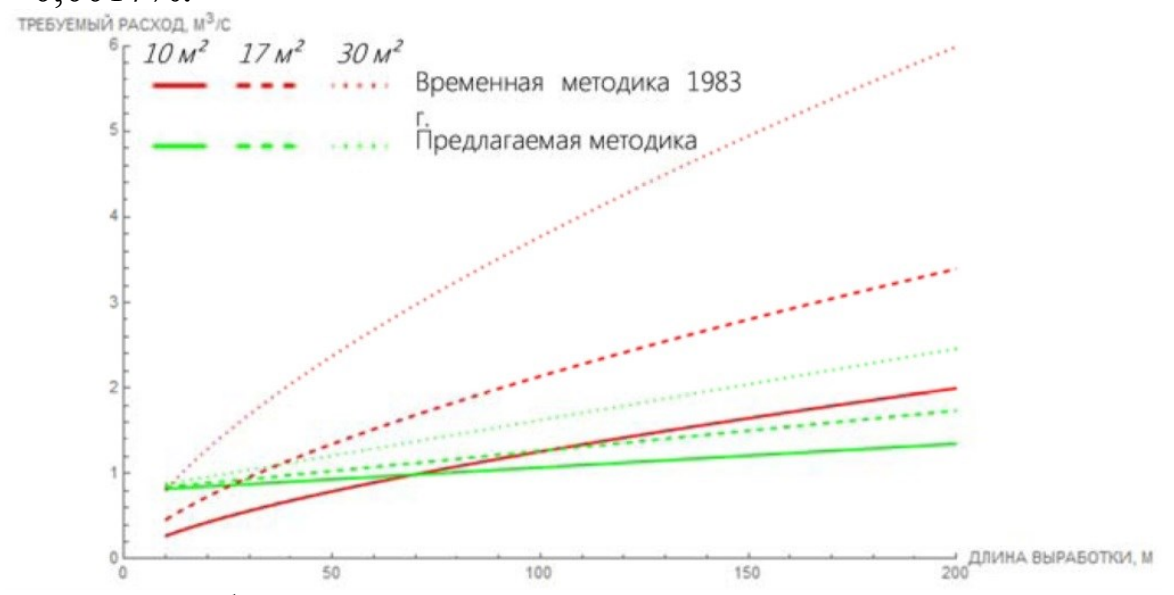

Рис. 4. Зависимость требуемого расхода для проветривания тупиковой проходческой выработки после взрывных работ от длины выработки для сечений $10 \mathrm{~m}^{2}, 16 \mathrm{~m}^{2}, 30 \mathrm{~m}^{2}$.

Из графиков видно, что формула временной методики 1983 г. дает в большинстве случаев завышенные значения требуемого расхода. Это связано в основном с тем, что в этой формуле вся выработка принимается в качестве зоны смешения вне зависимости от ее длины.

В формуле (8) первое слагаемое учитывает турбулентное перемешивание в зоне смешения выработки, а второе - конвективный вынос вредных примесей из оставшейся части выработки. Такой подход позволяет, во-первых, учитывать различные механизмы вентиляции тупиковой выработки, а во-вторых, энергоэффективно использовать свежий воздух, поступающий на проветривание рудника.

\section{БИБЛИОГРАФИЧЕСКИЙ СПИСОК}

1. Ушаков К.З. Газовая динамика шахт. - М.: Изд-во МГГУ, 2004. - 480 с.: ил.

2. Воронин В.Н. Основы рудничной аэро-газодинамики. - М.: Л.: Углетехиздат, 1951. - 492 с.: ил.

3. Carriere R.. McGuire C.. McLaren E., Witow D. Studying operational improvements in blast gas clearing using ventilation control // Proceedings of the $16^{\text {th }}$ North American Mine Ventilation Symposium. - Colorado, 2017. - P. 19.7-19.16.

4. Левин Л.Ю., Исаевич А.Г., Семин М.А., Газизуллин Р.Р. Исследование динамики пылевоздушной смеси при проветривании тупиковой выработки в процессе работы комбайновых комплексов // Горн. журн. - 2015. - № 1. - С. 72-75. 
5. Колесов Е.В. Обоснование последовательного проветривания рабочих зон нескольких тупиковых выработок // Стратегия и процессы освоения георесурсов: сб. науч. тр. Вып. 16 / ГИ УрО РАН. Пермь, 2018. - C. 291-295. DOI: 10.7242/gdsp.2018.16.78

6. Tariq F., Bekir G. Evaluation of line brattice length in an empty heading to improve air flow rate at the face using CFD // International Journal of Mining Science and Technology. - 2017. - V. 27, № 2. - P. 253-259. DOI: $10.1016 /$ j.ijmst.2017.01.012

7. Torno S., Torano J., Ulecia M., Allende C. Conventional and numerical models of blasting gas behaviour in auxiliary ventilation of mining headings // Tunnelling and Underground Space Technology. - 2013. - V. 34. - P. 73-81. DOI: 10.1016/j.tust.2012.11.003

\title{
ИССЛЕДОВАНИЕ ГАЗОВОГО СОСТАВА РУДНИЧНОГО ВОЗДУХА ДЛЯ ОЦЕНКИ ВОЗМОЖНОСТИ ПРИМЕНЕНИЯ РЕЦИРКУЛЯЦИОННОГО ПРОВЕТРИВАНИЯ
}

\author{
Н.А. ТРУШКОВА \\ Горный институт УрО РАН, г. Пермь
}

\begin{abstract}
Аннотация: В работе представлены результаты исследований газового состава рудничного воздуха на калийных и медно-никелевых рудниках. В настоящее время рециркуляционное проветривание применяется только на калийных рудниках. На других рудниках, где применение рециркуляции не разрешено, все чаще возникает такая потребность, имеющая целью повышение качества проветривания рабочих зон и снижение количества потребляемой энергии. В данной работе проведен сравнительный анализ качества воздуха исходящей струи на калийных и медно-никелевых рудниках (Норильский никель), на основании которого сделана оценка возможности применения рециркуляционного проветривания.

Ключевые слова: схема проветривания, рудничный воздух, газовыделение, свежая струя, исходящая струя, рециркуляция, предельно-допустимая концентрация.
\end{abstract}

\section{Введение}

Рост производственных мощностей и развитие вентиляционных систем рудников приводит к тому, что зачастую главные вентиляторные установки и системы воздухоподготовки работают в режиме максимальной производительности для обеспечения рабочих зон требуемым количеством воздуха. Возникают участки, испытывающие дефицит воздуха, а увеличение подачи в рудник свежего воздуха невозможно по техническим характеристикам вентиляторов. Все чаще на рудниках возникает потребность в применении рециркуляции для повышения качества проветривания рабочих зон и снижения количества потребляемой энергии на проветривание и воздухоподготовку. Нормативными документами разрешено применение рециркуляции только на калийных рудниках, однако прямого запрета на использование рециркуляционных систем на других рудниках нет [1].

При применении рециркуляции часть отработанного воздуха за счет работы вспомогательного вентилятора подается на свежую струю и используется повторно. Безопасность и эффективность применения рециркуляции для повышения качества проветривания добычных участков и снижения энергозатрат на проветривание установлена на основании исследований газового состава рудничной атмосферы калийных рудников и динамики распространения газовых примесей, описанных в [2]. В настоящее время эффективность применения рециркуляции доказана на практике и системы частичного повторного использования воздуха широко применяются на калийных рудниках [3-9].

\section{Результаты исследований газового состава воздуха на руднике БКПРУ-4}

С целью определения газовой динамики на руднике БКПРУ-4 ПАО «Уралкалий» специалистами отдела Аэрологии и теплофизики ГИ УрО РАН выполнена серия измерений газового состава воздуха для оценки распространение метана и сероводорода в вентиляционной сети (газы, выделяющиеся при добыче). Измерения выполнялись на всех главных направлениях рудника в различные периоды года по маршруту от воздухоподающего ствола до вентиляционного через рабочие зоны, где происходит выделение вредностей (рис. 1).

По результатам измерений определена динамика распространения газовых примесей для всех направлений рудника, максимальные концентрации газов зафиксированы на Юговосточном направлении, результаты замеров приведены на рис. 2 для метана и сероводорода. 